\title{
WHAT ROLE FOR THE CAP IN MAKING AGRICULTURE PART OF THE EU CIRCULAR ECONOMY?
}

\author{
Barbara Wieliczko ${ }^{\bowtie}$ \\ Institute of Agricultural and Food Economics - National Research Institute, Poland
}

\begin{abstract}
The concept of circular economy has been gaining in popularity and interest among both scholars and policymakers. It is an alternative to today's linear system and it focuses on reducing waste and minimizing the use of resources. The purpose of this paper is to present the challenges related to agricultural transformation towards circular economy, and to analyze the scope and nature of solutions that could be used under the CAP to support the integration of EU agriculture into the circular economy system. The study is based on a review of papers on circular economy (CE). The review enabled identifying the particularities of $\mathrm{CE}$ which showed the potential role for the $\mathrm{CAP}$ in implementing $\mathrm{CE}$ in agriculture. The conclusions from the research indicate that CAP instruments currently in place have a limited potential to support the adaptation of agriculture to the circular economy. However, it is possible to modify the support criteria so that they stimulate the integration of the EU agricultural sector into the economy model implemented in the EU. However, to accelerate this process, it is necessary to introduce more effective instruments in providing ecosystem services and mechanisms of cooperation with the industry.
\end{abstract}

Keywords: EU agriculture, CAP, circular economy, policy impact

\section{INTRODUCTION}

There is a growing interest in the concept of circular economy (CE) as it offers an alternative to an unsustainable system of constant growth based on unlimited use of resources (Jurgilevich et al., 2016). Thus, it is restorative by intention (Genovese et al., 2017). The implementation of production models offering higher efficiency and lower pollution levels thanks to closedloop systems is gaining support from policymakers. In the research on the effects of different economic activities, life cycle assessment is often used to evaluate their actual impact on the environment (Noya et al., 2017; Scheepens et al., 2015).

The EU has been actively introducing the concept of circular economy into its policies. This is because circular economy is seen as a way to face the challenges of climate changes and depleting resources. The process of transforming the EU into a circular economy started with the European Commission's communication on waste-Towards a circular economy: a zero waste program for Europe (COM(2014)398). This is closely linked with another concept strongly advocated by the European Commission (EC), namely the bioeconomy.

There are numerous definitions of circular economy (also known as closed-loop economy) emphasizing different aspects of this concept (Kirchherr et al., 2017). Based on a literature review, Geissdoerfer et al. (2017) proposed their own definition of circular economy as "a regenerative system in which resource input and waste, emission, and energy leakage are minimized by slowing, closing, and narrowing material and energy loops," which "can be achieved through long-lasting design, maintenance, repair, reuse, remanufacturing, refurbishing, and recycling." Circular economy has its roots in ecological and environmental economics as well as in

\footnotetext{
$\bowtie$ Barbara Wieliczko, PhD, Institute of Agricultural and Food Economics - National Research Institute, Świętokrzyska 20 St., 00-002 Warsaw, Poland, e-mail: wieliczko@ierigz.waw.pl, https://orcid.org/0000-0003-3770-0409
} 
industrial ecology (Ghisellini et al., 2016). Other named origins include performance economy, regenerative design, biomimicry, the cradle to cradle concept and blue economy (Geissdoerfer et al., 2017). This concept is also seen as a new business model (Naustdalslid, 2014). The concept is often associated with 3R: reduction, reuse and recycle ( $\mathrm{Su}$ et al., 2013). It is considered to be a viable development strategy reconciling economic development with environmental concerns (Heshmati, 2015). The key benefit of circular economy is that it leads to reduction of excessive waste and turns some of the waste into resources (Wysokińska, 2016).

In the case of agriculture, the transition into a circular economy means:

- producing agricultural commodities using a minimal amount of external inputs;

- closing nutrient loops and reducing negative discharges to the environment;

- valorizing agri-food wastes (Ward, 2017).

There is not much progress in reshaping the economy to make it a circular one. This is because the transformation into a circular economy is hindered by a number of barriers, including:

- lack of incentives due to the fact that current resource prices do not include the costs of external effects such as pollution;

- lack of funds for investment in circular technologies and products;

- lack of public awareness and pressure;

- lack of coherent policy supporting the transformation into circular economy.

Moreover, the lack of clarity can be a barrier to CE's popularization. Kalmykova et al. (2018) "argue that dissemination of the circular economy is hampered because the CE field is currently populated by diverging approaches."

As stated by Donia et al. (2018), "applying the principle of circular economy to agriculture is a very important contemporary issue." The primary reason for the above is the constant depletion of resources that are vital for agricultural production.

To answer the question formulated in the title, two other problems have to be tackled. These are the following questions:

- What is CE and what are its benefits?
- Is there potential for making agriculture part of the circular economy?

- How can the CAP support transformation of the EU agriculture into a circular sector?

Therefore, in the "results" section, the replies to these two questions are presented, while the "discussion" section answers the title question.

\section{MATERIAL AND METHODS}

The paper is based on a literature review. The materials studied are the publications on circular economy, experiences with its implementation, the role of public policy in introducing the circular economy, and the EU documents on circular economy initiatives. The literature review allowed to:

- clarify the current state of art on the concept of CE,

- identify the advantages of and barriers to its implementation, both in the general economy and in the agricultural sector,

- present the role of public policy in the transformation towards CE.

\section{RESULTS}

Circular economy transfers the approach towards valueadded chains from an open-ended conception to a cyclical one (Wuebbeke and Heroth, 2014), and can offer benefits relating to environment, economy and society. These include (Korhonen et al., 2018a):

1. Environmental win:

- reduced virgin material and energy input;

- virgin inputs are predominantly (to the extent possible) renewable from productive ecosystems;

- reduced waste and emissions;

- resources in production-consumption systems are reused instead of being used only once;

- renewables are $\mathrm{CO}_{2}$-neutral fuels; their wastes are nutrients that can be used by nature.

2. Social win:

- new employment opportunities through new uses of value embedded in resources;

- increased sense of community, cooperation and participation through the sharing economy; 
- user groups share the function and service of a physical product instead of individuals owning and consuming the physical product.

3. Economic win:

- reduced raw material and energy costs;

- resource value is reused instead of being used only once;

- minimized use of costly scarce resources;

- reduced costs that arise from environmental legislation, taxes and insurance;

- image, responsibility and green market potential;

- reduced value leaks and losses;

- reduced waste management costs;

- reduced emission control costs;

- reduced costs of environmental legislation, taxation and insurance;

- new markets found for the value in resources;

- new responsible business image that attracts investment.

Yet, certain limits and challenges need to be faced when implementing the circular economy concept. Korhonen et al. (2018a) point to the following problems:

- thermodynamic limits: cyclical systems consume resources and create wastes and emissions;

- system boundary limits: spatial limits - problems are shifted along the product life cycle; temporal limits - short term non-renewables use can build long-term renewable infrastructure;

- limits posed by the physical scale of the economy;

- rebound effect ${ }^{1}$, Jevons' paradox, boomerang effect ${ }^{2}$;

- limits posed by path-dependency and lock-in: the technologies retain their market position despite of inefficiency;

- limits of governance and management: intra-organizational and intra-sectoral management of interorganizational and inter-sectoral physical flows of materials and energy;

${ }^{1}$ The rebound effect (also called the take-back effect) is related to Jevon's paradox. Some researchers treat the two as synonyms. Both phenomena are related to energy and conservation economics. They imply that the improvement in technology is not fully translated into a more efficient resource use. This is a result of both substitution and income effects. More about the rebound effects and its types can be found in Freeman, 2018.

${ }^{2}$ The boomerang effect is an umbrella term for unintended consequences.
- limits of social and cultural definitions: the concept of waste.

Problems related to climate change and depleting resources affect the European Union's agricultural sector, too. The most dangerous seems to be the impact of climate change on water availability. Moreover, the agricultural sector - as a producer of negative externalities - must be included in the efforts towards reducing greenhouse gas emissions. These issues are already part of the EC's regulatory plans. In the Commission Work Program 2018 "An agenda for a more united, stronger and more democratic Europe" (COM(2017)650), the EC emphasized the need to include agriculture in the system of reducing GHG emissions.

\section{DISCUSSION}

CE is still not a clearly defined term. In fact, "CE appears as an umbrella concept" (Merli et al., 2018). As stated by Korhonen et al. (2018a), the concept of circular economy is "superficial and unorganized." This has many consequences, including the difficulty in determining its relationship with sustainable development. It can be supposed that circular economy is a tool for the achievement of sustainable development goals. Yet, a literature review conducted by Geissdoerfer et al. (2017) shows that the relationship between circular economy and sustainable development is unclear. There are certain similarities and differences that can be enumerated. Among similarities Geissdoerfer et al. (2017) list:

- the need for cooperation between different stakeholders;

- intra- and intergenerational commitments;

- integrating non-economic aspects into development;

- importance of technological solutions;

- core role of regulations and incentives as implementation tools;

- the role of system change and innovations.

However, the differences seem to be more profound. The circular economy focuses on environmental issues and economic benefits, while sustainable development is a holistic concept encompassing not only the environment, but also economic and social aspects of developmental issues. Yet, it must be borne in mind that the circular economy concept is at a different stage of development than the sustainable development concept, 
and that social aspects of circular economy start to be present is research on circular economy (Korhonen et al., 2018a). Moreover, moving towards a CE is "contingent on 'systemic' EI (Eco-Innovation), that is, not only intense in technology but also involving dynamic and holistic combinations of service innovations and novel organizational set-ups" (de Jesus et al. 2018). Yet, it must be borne in mind that "without an evaluation framework or bottom-up support from the industry or the community, CE initiatives are not sustained" (Winans et al., 2017).

An important issue when assessing the role of agriculture in circular economy is soil management. Breure et al. (2018) stated that "the recovery and reuse of land and soil is necessary to secure the future provision of natural resources and services for a growing world population." Therefore, the agricultural policy should tackle this matter. Especially important is the question of erosion and soil condition. It may be addressed by different policy measures and obligations which can be a condition for granting support.

The role of public policies in turning the economy into a circular one is supporting the bottom-up initiatives. As stated by Genovese et al. (2017) "external stakeholders (such as local and central governments, governmental agencies, industrial bodies) could play a "facilitator" role by helping the matching of virgin resources demand and equivalent by-products supply, by developing integrated approaches to eco-industrial development." The role of public bodies is seen similarly by Reike et al. (2018) who stated that "government and policymakers have a key role in enabling mechanisms for shorter loop value retention options, setting targets, and in directing economic activities towards more circularity."

The extent of changes needed at the farm level (as well as in the other parts of the agricultural sector) depends on the specific product or production type. This means that different parts of the system require different solutions and different stimuli.

The reshaping of the economy is not an easy process. To make sure that new methods, technologies and processes are actually beneficial, specific measurement and assessment methods have to be applied. The most widely used include: Life Cycle Assessment (LCA), Life Cycle Costing (LCC) and social Life Cycle Assessment (S-LCA). There are also other popular methods for analyzing different aspects of CE (Table 1). "However, the state of the art shows that a deep research on CE assessment and indicators is still lacking, in particular on the micro level" (Elia et al., 2017). New methods for measurement are also being developed such as the value-based resource efficiency (VRE) indicator (Di Maio et al., 2017).

The issues related to environment also appeared in the EC's communication on the future of the CAP - The Future of Food and Farming (European

Table 1. Taxonomy of index-based methods

\begin{tabular}{lll}
\hline \multicolumn{1}{c}{ Parameter } & \multicolumn{1}{c}{ Single indicator } & \multicolumn{1}{c}{ Multiple indicator } \\
\hline Material flow & $\begin{array}{l}\text { Water footprint } \\
\text { Material Inputs per Unit of Service } \\
\text { Ecological Rucksack }\end{array}$ & $\begin{array}{l}\text { Material Flow Analysis } \\
\text { Substance Flow Analysis }\end{array}$ \\
Energy flow & $\begin{array}{l}\text { Cumulative Energy Demand } \\
\text { Embodied Energy }\end{array}$ & \\
& Energy Analysis \\
& Exergy Analysis & \\
Land use and & $\begin{array}{l}\text { Ecological Footprint } \\
\text { consumption }\end{array}$ & Sustainable Process Index \\
& Dissipation Area Index & \\
Other life cycle & Carbon Footprint & \\
based & Ecosystem Damage Potential & Life Cycle Assessment \\
& & Environmental Performance Strategy Map \\
& & Sustainable Environmental Performance Indicator \\
\hline
\end{tabular}

Source: Elia et al., 2017, Fig. 2. 
Commission, 2017b). In this document, the EC underlined that agriculture should make "a fair contribution" to achieving the EU 2030 Climate and Energy targets. In the case of non-ETS sectors, the decrease in GHG emissions is supposed to reach $30 \%$ of what was recorded in 2005. The EC has already presented a proposal for the inclusion of the land use sector into the reduction of GHG emissions (European Commission, 2016) but it has not yet become a regulation in force. However, the Common Agricultural Policy (CAP) after 2020 is expected to "reflect higher ambition and focus more on results as regards resource efficiency, environmental care and climate action" (European Commission, 2017b). Moreover, the EC stated in its communication on the CAP that "the CAP must continue stepping up its response to these challenges and it also shall play an essential role in realizing the Juncker priorities in full coherence with other policies, especially (...) the circular economy and the bioeconomy while bolstering environmental care and fighting and adapting to climate change." The European Commission stated that "the transition to a circular economy is a tremendous opportunity to transform our economy and make it more sustainable, contribute to climate goals and the preservation of the world's resources, create local jobs and generate competitive advantages for Europe in a world that is undergoing profound changes" (European Commission, 2018).

The EC also stated that circular economy offers "opportunities for farmers and rural businesses to diversify their businesses, hedge risks and provide additional income." Therefore, "the policy should increasingly focus on supporting such efforts" (European Commission, 2017b). In the EC's opinion, the CAP can also have a role in turning the EU into CE as it "can help to reduce food waste and food losses by stimulating better production and processing practices (e.g. promoting new technologies that extend the shelf life of perishable products or better matching supply and demand through increased transparency) and by supporting initiatives that transform traditional produce-use-discard consumption patterns into a circular bioeconomy" (European Commission, 2017b).

An important issue related to the $\mathrm{CE}$ in agriculture is the system of agri-environmental statistics that is needed to assess the progress made towards $\mathrm{CE}$. The focus of the 2012-2027 CAP on an evidence-based policy can initiate the works needed to supplement public statistics with data that can enable monitoring CE's implementation. This is especially important in the context of implementing such a system-transforming concept as the CE.

The regulations proposed by the EC for the 20212027 CAP do not offer a significant change in the functioning of CAP that would be needed to make EU agriculture part of the EU circular economy. This means that the CAP will continue to be more of a barrier than a catalyst for circular economy. As Ritzén and Sandström (2017) stated, barriers to the circular economy include financial, structural, operational, attitudinal and technological ones. The CAP can be active in all these fields but it is not focused on circular economy so it can only indirectly support the CE. Yet, it also supports maintaining the status quo, which means that it hinders transition into the circular economy.

Still, the difficulties related to transformation of the whole agri-food system towards CE must be strongly emphasized. The omnipresent efforts to become and remain competitive put farmers on the path of specialization to gain competitiveness through the economies of scale. While this improves their competitiveness, it generally is detrimental to sustainability and makes the circular farming processes impossible. Organic farming is, in a way, a method to tackle this problem but it is still imperfect and it seems not to be a solution and a direct way of transforming agriculture towards CE.

\section{CONCLUSIONS}

The need for reducing the adverse environmental impacts of economic activity is constantly growing. Despite the EC's declarations, the transformation of the EU into a circular economy has not yet gained enough pace. It is evident that the transformation process requires a joint effort of all the EU and member states policies at all levels. It also seems that the next step that needs to be taken at the EU level is the inclusion of all of the EU policies into the effort. The approaches adopted in separate EU policies must be coordinated with other policies and strategies.

In the case of the agricultural sector, all the actors and stakeholders of the food chain must be actively involved in circular economy processes.

Despite its growing popularity, the $\mathrm{CE}$ remains more of a concept and visionary ideal than a really implemented holistic development strategy. This results in lack of business models and policy instruments that be 
seen as good practices worth disseminating. Therefore, there is no wonder that the EC's proposals concerning the 2021-2027 CAP are not strictly and directly focused on CE's implementation. Yet, as environmental issues are to become even more important, this should give a boost to more environmentally-friendly practices that are in line with CE.

Naturally, the role for the CAP varies depending on the actors and the issue. Yet, there is much room for the CAP to support the transformation towards circular economy. The most important areas the CAP can actively support while promoting the circular economy are:

- education;

- cooperation among different stakeholders in order to create and disseminate innovations;

- investment;

- creation of short supply chains.

Summing up, it can be stated that due to the fact that $\mathrm{CE}$ must encompass a whole plethora of different concepts and issues often associated with "sustainable development" so popular in the context of agriculture, it is not strongly called for within the CAP. Yet, emphasis on environmental issues and innovations related to the need for higher resource efficiency and adaptation to climate change should contribute to making the EU agriculture part of the CE.

\section{SOURCE OF FINANCING}

This paper is the outcome of "The Polish and the EU agricultures $2020+$. Challenges, chances, threats, proposals," the internal 2015-2019 Multi-Annual Program of the Institute of Agricultural and Food Economics National Research Institute based in Warsaw.

\section{REFERENCES}

Breure, A. M., Lijzen, J. P. A., Maring, L. (2018). Soil and land management in a circular economy. Sci. Total Env., $624,1125-1130$.

De Jesus, A., Antunes, P., Santos, R., Mendonça, S. (2018). Eco-innovation in the transition to a circular economy: An analytical literature review. J. Cleaner Prod., 172, 2999-3018.

Di Maio, F., Rem, P. C., Baldé, K., Polder, M. (2017). Measuring resource efficiency and circular economy: A market value approach. Res. Cons. Rec., 122, 163-171.
Donia, E., Mineo, A. M., Sgroi, F. (2018). A methodological approach for assessing businness investments in renewable resources from a circular economy perspective. Land Use Policy, 76, 823-827.

Elia, V., Gnoni, M. G., Tornese, F. (2017). Measuring circular economy strategies through index methods: A critical analysis. J. Clean. Prod., 142, 2741-2751.

European Commission (2014). Communication from the Commission to the European Parliament, the Council, the European Economic and Social Committee and the Committee of the Regions - Towards a circular economy: A zero waste programme for Europe, COM(2014)398.

European Commission (2016). Proposal for a regulation of the European Parliament and of the Council on the inclusion of greenhouse gas emissions and removals from land use, land use change and forestry into the 2030 climate and energy framework and amending Regulation No 525/2013 of the European Parliament and the Council on a mechanism for monitoring and reporting greenhouse gas emissions and other information relevant to climate change, COM(2016)479.

European Commission (2017a). Communication from the Commission to the European Parliament, the Council, the European Economic and Social Committee and the Committee of the Regions - Commission Work Programme 2018 "An agenda for a more united, stronger and more democratic Europe", COM(2017)650.

European Commission (2017b). Communication from the Commission to the European Parliament, the Council, the European Economic and Social Committee and the Committee of the Regions - The Future of Food and Farming, $\operatorname{COM}(2017) 713$.

European Commission (2018). Communication from the Commission to the European Parliament, the Council, the European Economic and Social Committee and the Committee of the Regions on a monitoring framework for the circular economy, COM(2018)16.

Freeman, R. (2018). A Theory on the Future of the Rebound Effect in a Resource-Constrained World. Front. Ener. Res., 6,81 .

Geissdoerfer, M., Savaget, P., Bocken, N., Hultink, E. J. (2017). The Circular Economy - A new sustainability paradigm? J. Clean. Prod., 143, 757-768.

Genovese, A., Acquaye, A. A., Figueroa, A., Koh, S. C. L. (2017). Sustainable supply chain management and the transition towards a circular economy: Evidence and some applications. Omega, 66, 344-357.

Ghisellini, P., Cialani, C., Ulgiati, S. (2016). A review on circular economy: the expected transition to a balanced interplay of environmental and economic systems. J. Clean. Prod., 114, 11-32. 
Heshmati, A. (2015). A Review of the Circular Economy and its Implementation, IZA Discussion Papers, No. 9611. Bonn: Institute for the Study of Labor (IZA).

Jurgilevich, A., Birge, T., Kentala-Lehtonen, J., KorhonenKurki, K., Pietikäinen, J., Saikku, L., Schösler, H. (2016). Transition towards circular economy in the food system. Sustainability, 8(1), 69.

Kalmykova, J., Sadagopan, M., Rosado, L. (2018). Circular economy - From review of theories and practices to development of implementation tools. Res. Conser. Rec., 135, 190-201.

Kirchherr, J., Reike, D., Hekkert, M. (2017). Conceptualizing the circular economy: An analysis of 114 definitions. Res. Conser. Rec., 127, 221-232.

Korhonen, J., Honkasalo, A., Seppälä, J. (2018a). Circular Economy: The Concept and its Limitations. Ecol. Econ., 143, 37-46.

Korhonen, J., Nuur, C., Feldmann, A., Birkie, S. E. (2018b). Circular economy as an essentially contested concept. J. Clean. Prod., 175, 544-552.

Merli, R., Preziosi, M., Acampora, A. (2018). How do scholars approach the circular economy? A systematic literature review. J. Clean. Prod., 178, 703-722.

Naustdalslid, J. (2014). Circular economy in China e the environmental dimension of the harmonious society. Int. J. Sust. Dev. World Ecol., 21(4), 303-313.

Noya, I., Alde, X., González-García, S., Gasol, C. M., Moreira, M. T., Amores, M. J., Marín, D., Boschmonart-Rives, J. (2017). Environmental assessment of the entire pork value chain in Catalonia - A strategy to work towards Circular Economy. Sci. Total Env., 589, 122-129.
Reike, D., Vermeulen, W. J. V., Witjes, S. (2018). The circular economy: New or Refurbished as CE 3.0? - Exploring Controversies in the Conceptualization of the Circular Economy through a Focus on History and Resource Value Retention Options. Res. Cons. Rec., 135, 246-264.

Ritzén, S., Sandström, G. O. (2017). Barriers to the Circular Economy - integration of perspectives and domains. Procedia CIRP, 64, 7-12.

Scheepens, A. E., Vogtländer, J. G., Brezet, J. C. (2015). Two life cycle assessment (LCA) based methods to analyse and design complex (regional) circular economy systems. Case: making water tourism more sustainable. J. Clean. Prod., 114, 257-268.

Su, B., Heshmati, A., Geng, Y., Yu, X. (2013). A review of the circular economy in China: moving from rethoric to implementation. J. Clean. Prod., 42, 215-277.

Ward, S. (2017). The 'circular economy' applied to the agrifood sector. Presented at The European Commission DG Research \& Innovation hosted conference on: 'Harnessing Research and Innovation for FOOD 2030: A Science Policy Dialogue' 16 October 2017, Brussels.

Winans, K., Kendall, A., Deng, H. (2017). The history and current applications of the circular economy concept. Renew. Sust. Energy Rev., 68, 825-833.

Wuebbeke, J., Heroth, T. (2014). Challenges and political solutions for steel recycling in China. Res. Cons. Rec., 87, $1-7$.

Wysokińska, Z. (2016). The "New" Environmental Policy of the European Union: A Path to Development of a Circular Economy and Mitigation of the Negative Effects of Climate Change. Comp. Econ. Res., 19(2), 57-73. 